\title{
Changes in the genomic content of circulating Bordetella pertussis strains isolated from the Netherlands, Sweden, Japan and Australia: adaptive evolution or drift?
}

\author{
Audrey J King ${ }^{1 *}$, Tamara van Gorkom , Han GJ van der Heide ${ }^{1}$, Abdolreza Advani², Saskia van der Lee ${ }^{1}$
}

\begin{abstract}
Background: Bordetella pertussis is the causative agent of human whooping cough (pertussis) and is particularly severe in infants. Despite worldwide vaccinations, whooping cough remains a public health problem. A significant increase in the incidence of whooping cough has been observed in many countries since the 1990s. Several reasons for the re-emergence of this highly contagious disease have been suggested. A particularly intriguing possibility is based on evidence indicating that pathogen adaptation may play a role in this process. In an attempt to gain insight into the genomic make-up of $B$. pertussis over the last 60 years, we used an oligonucleotide DNA microarray to compare the genomic contents of a collection of 171 strains of $B$. pertussis isolates from different countries.

Results: The CGH microarray analysis estimated the core genome of B. pertussis, to consist of 3,281 CDSs that are conserved among all B. pertussis strains, and represent $84.8 \%$ of all CDSs found in the 171 B. pertussis strains. A total of 64 regions of difference consisting of one or more contiguous CDSs were identified among the variable genes. CGH data also revealed that the genome size of $B$. pertussis strains is decreasing progressively over the past 60 years. Phylogenetic analysis of microarray data generated a minimum spanning tree that depicted the phylogenetic structure of the strains. B. pertussis strains with the same gene content were found in several different countries. However, geographic specificity of the B. pertussis strains was not observed. The gene content was determined to highly correlate with the ptxP-type of the strains.

Conclusions: An overview of genomic contents of a large collection of isolates from different countries allowed us to derive a core genome and a phylogenetic structure of B. pertussis. Our results show that B. pertussis is a dynamic organism that continues to evolve.
\end{abstract}

\section{Background}

Bordetella pertussis is the causative agent of whooping cough, a highly contagious disease of the respiratory tract in humans. B. pertussis and the closely related $B$. parapertussis have diverged independently by genome decay of a $B$. bronchiseptica-like ancestor $[1,2]$. The three species have much in common, including a high degree of sequence similarity in shared genes. However,

\footnotetext{
* Correspondence: audrey.king@rivm.nl

'Laboratory for Infectious Diseases and Screening (LIS) Centre for Infectious Disease Control, National Institute for Public Health and the Environment RIVM - Netherlands, P.O. Box 1, 3720 BA Bilthoven, The Netherlands
}

they differ in several respects such as severity of disease and host range specificity [3-6].

Extensive immunization of children reduced the incidence of serious disease and mortality caused by B. pertussis [7]. However, globally, pertussis remains a leading cause of vaccine preventable hospitalizations and deaths in children $[8,9]$. In the last decade, a resurgence of pertussis, especially among adolescents and adults, has been observed in many industrialized countries with a high vaccination coverage [10-12]. Numerous studies have demonstrated that the $B$. pertussis population has changed since the 1950s. Waning immunity, in combination 
with pathogen adaptation, may have contributed to the continued circulation of B. pertussis strains [13-18].

In most industrialized countries, generalized vaccination with a whole cell pertussis vaccine (WCV) began between 1950 and 1960. However, in the late 1970s, concerns over vaccination side effects led to changes in the vaccine composition, vaccine uptake, or temporary exclusion of pertussis whole cell immunization in some countries $[19,20]$. In order to tackle this problem, the development of an acellullar pertussis vaccine (ACV) exhibiting fewer side effects started in the 1980s. Immunization schedules and the type of vaccine used began to differ in each country, leading to disparities in pertussis vaccination histories. In the Netherlands, pertussis vaccination, using a WCV produced by the Netherlands Vaccine Institute, was introduced in 1953. From 1975 to 1985 a lower vaccine dose was used, which most likely lead to an increase in the incidence of pertussis between 1985 to 1987 [21]. After restoring the vaccine to the normal dose, a lower incidence of pertussis was noted until 1996. However, since 1996, the pertussis incidence has increased. Furthermore, pertussis epidemics have been frequently observed every 3-5 years. In 2005, the Netherlands ceased using WCVs and switched to using an ACV for primary and booster vaccinations. In Sweden, a WCV was used from 1953 until 1978. From 1979 to 1996 , pertussis vaccinations were not administered. Since 1996, ACVs are used for pertussis vaccination in Sweden [22,23]. The Japanese population received the WCV from 1949 until 1981, at which time an ACV was introduced [24,25]. In Australia, a WCV had been used until 1997. However, in the late 1970's, the vaccine was not administered as frequently due to the population's decrease in confidence of the vaccine. Since 1999, and continuing until today, an ACV is used [26]. Senegal began large scale pertussis vaccinations with a WCV in the late 1980 s, but the vaccination coverage was low [27]. The pertussis vaccination coverage in Kenya has also been relatively low $[28,29]$.

A large number of techniques have been used to type B. pertussis. Commonly used methods are pulsed field gel electrophoresis (PFGE), Multi-Locus Sequence Typing (MLST) and Multiple-Locus Variable number of Tandem Repeat Analysis (MLVA) [23,30-37]. These methods have generally been effective for grouping strains of B. pertussis. However, some of these methods are very laborious, or have little discriminatory potential to elucidate the phylogenetic relationships of the strains.

Microarray technology, combined with mathematical analysis to determine phylogeny, has provided a sensitive and robust method to examine the genetic relatedness of bacterial populations [38-41]. Comparative genomic hybridizations $(\mathrm{CGH})$ using genome-wide DNA microarrays have proven useful in studies of intraspecies diversity for a number of bacterial species [39]. Also, several microarray-platforms have been applied to specifically address questions related to the genome of $B$. pertussis [1,42-45]. In a previous study, we have used microarray-based CGH to determine the genomic characteristics of the $B$. pertussis strain involved in the Dutch 1996-2004 epidemic [45].

In this study, we sought to analyze the changes of the B. pertussis population in the Netherlands and five other countries, with different vaccination histories between 1949 and 2008. To this end, we determined the gene content of B. pertussis strains by using microarray-based $\mathrm{CGH}$. The overview of gene content in a large collection of global isolates obtained from the CGH data enabled us to define the core genome of the $B$. pertussis species, and to construct a phylogenetic structure of $B$. pertussis. Furthermore, it gives us a better understanding of the dynamics of the $B$. pertussis strains circulating in the immunized population. Insight into the polymorphism of $B$. pertussis and its capacity to adapt to population immunity is important in the understanding of pertussis epidemiology.

\section{Results}

\section{Strain collection}

In this study, we analyzed $171 \mathrm{~B}$. pertussis isolates by microarray-based $\mathrm{CGH}$ in order to investigate the dynamics of $B$. pertussis gene content, and possibly reveal temporal and geographic differences. We used a collection of 171 strains from six different countries (the Netherlands, Sweden, Australia, Kenya, Senegal and Japan) isolated between 1949-2008. The collection was divided into several time periods, chosen around significant events in the pertussis vaccination history of a particular country (Table 1). No strains were available in the post ACV period in Australia or from the vaccine free period in Senegal. The majority of the strains are isolated from the Netherlands; these strains should represent a sufficient number of $B$. pertussis populations in the Netherlands. We selected all strains based on frequency dependent selection using MLST type or PFGE type to avoid a selection bias. The Dutch strains of $B$. pertussis were typed in previous studies for MLST [45] [Mooi, unpublished results], while the Swedish strains were typed by PFGE [46]. The strains that were not typed in previous studies were typed in this study (not shown).

\section{Microarray}

We used two different microarrays to analyze the gene content of the B. pertussis strains. Forty-two percent of the strains were analyzed by a previously validated $B$. pertussis oligonucleotide microarray based on the Tohama I genome [45], while the remaining $58 \%$ of the 
Table 1 Vaccination history of different countries

\begin{tabular}{|c|c|c|c|c|}
\hline Country & Period & Comment & Year of Isolation & Number of strains \\
\hline Netherlands & NV & vaccine strains & & 2 \\
\hline Netherlands & $\mathrm{N} 1$ & pre-vaccination period & 1949-1953 & 11 \\
\hline Netherlands & N2 & Early post vaccine WCV & 1953-1964 & 5 \\
\hline Netherlands & N3 & late post vaccine WCV & 1965-1975 & 6 \\
\hline Netherlands & N4 & vaccine dose reduction period & 1976-1984 & 16 \\
\hline Netherlands & N5 & post vaccine dose reduction period & 1985-1992 & 15 \\
\hline Netherlands & N6 & Epidemic & 1993-2004 & 31 \\
\hline Netherlands & N7 & Early post ACV & $2005-2008$ & 18 \\
\hline Sweden & Sw1 & Post WCV & 1953-1978 & 5 \\
\hline Sweden & Sw2 & Vaccine free period & 1979-1996 & 7 \\
\hline Sweden & Sw3 & Post ACV & 1997-2008 & 8 \\
\hline Japan & J1 & Post WCV & 1949-1981 & 1 \\
\hline Japan & $J 2$ & Post ACV & $1982-2008$ & 7 \\
\hline Australia & $\mathrm{A} 1$ & Post WCV & 1950-1998 & 15 \\
\hline Australia & $A 2$ & Post ACV & 1999-2008 & - \\
\hline Senegal & Se1 & Vaccine free period & until 1987 & - \\
\hline Senegal & Se2 & Early post WCV & 1988-2008 & 10 \\
\hline \multirow[t]{2}{*}{ Kenya } & K1 & Vaccine free period & until 2008 & 13 \\
\hline & & Reference strain, Tohama I & & 1 \\
\hline
\end{tabular}

strains were analyzed by a new extended oligonucleotide microarray based on the $B$. pertussis sequences supplemented with the additional CDSs from $B$. parapertussis and B. bronchiseptica [47]. Nine (5\%) strains were analyzed using both microarrays. In total, 3,751 probes were included in the $B$. pertussis microarray and 5,910 probes were used in the extended Bordetella microarray (Additional file 1, Table S1a and Additional file 2, Table S1b). The efficacy of the extended Bordetella microarray was assessed in this study by the control hybridizations of reference DNA (genomic DNA from ATCC BAA-589 Tohama I) vs. reference DNA. The reference strain ATCC BAA-589 Tohama I did not hybridize to all probes on the microarray, since the array contains probes that are not present in this strain. The majority of the genes (99.83\%) in this strain were predicted to be present/conserved (data not shown). The nine strains tested on both microarrays gave similar predictions regarding the absence/divergence and presence/convergence of the genes that were observed in both microarrays. We confirmed the absence of the genes predicted to be absent/divergent by targeted PCR assays (see Materials \& Methods).

\section{Gene content, core genome and variable genes}

We have applied microarray-based CGH to $171 \mathrm{~B}$. pertussis strains in order to predict the gene content for these strains (Additional file 3, Table S2). In order to gain insight into which genes found previously in $\mathrm{Bp} /$ $\mathrm{Bpp}$ and $\mathrm{Bb}$ are present in the Bp species, we counted all of the different CDSs found in the 171 analyzed strains. The total number of CDSs predicted to be present in the isolates was 3,871 , (i.e. the pan-B. pertussis genome consists of 3,871 genes). However, the fully sequenced and annotated B. pertussis strain (Tohama I) was determined to have 3,816 CDSs, a difference of 55 CDSs. These extra genes are clustered in eight regions of difference (RDs) (Table 2). Five of these RDs had previously been found in $B$. pertussis strains [48]. Here, 12 new extra genes, forming three RDs, were identified in B. pertussis strains; BPP0474/BB0474, BPP0511-12/ BB0516-17 and BPP2338-47/BB1789-98 are also present in B. parapertussis strain 12822 and B. bronchiseptica strain RB50. Since the genes that are not present in the Tohama I genome were not observed in the $B$. pertussis microarray, all of the strains analyzed with this array were also screened by PCR for the eight RDs. In 99\% of the strains, the genes BPP0529-36, BPP0931-50, BPP4293-4301 and BPP0474 were present (Table 2). BPP0822-24 and BPP0825-27 were present in $85 \%$ or $86 \%$ of all strains tested, respectively. The genes BPP2338-47 and BPP0511-12 were found in only $6 \%$ of the $B$. pertussis strains (Table 2).

Of the 3,871 genes of the $B$. pertussis pan-genome, 513 genes $(13.3 \%)$ were detected as absent/divergent in one or more of the tested isolates, and were considered variable genes (Additional file 4, Table S3). The variable (non-core) genes formed a total of 64 RDs (Additional file 5, Table S4), each of them consisting of one or more contiguous CDSs. Sixty-seven percent of the 64 RDs were confirmed to be absent by targeted PCR assays or were also described by others (see Materials \& 
Table 2 Extra genes not found in Tohama I genome

\begin{tabular}{lccc}
\hline BPP and BB-number & No. of genes & Size (kb) & $\begin{array}{c}\text { Percentage of } \\
\text { presence }\end{array}$ \\
\hline BPP0474/BB0474 & 1 & 1 & $99 \%$ \\
BPP0511-12/BB0516-17 & 2 & 2 & $6 \%$ \\
BPP0529-36/BB0534-41 & 8 & 10.5 & $99 \%$ \\
BPP0822-24/BB0916-8 & 3 & 7.4 & $85 \%$ \\
BPP0825-27/BB0919-21 & 3 & 3.3 & $86 \%$ \\
BPP0931-950/BB1141-59 & 20 & 17 & $99 \%$ \\
BPP2338-47/BB1789-98 & 10 & 13.8 & $6 \%$ \\
BPP4293-4301/BB4880-88 & 9 & 9.1 & $99 \%$ \\
\hline
\end{tabular}

Methods) [42,44]. Our results demonstrated that most variable genes were present in more than $80 \%$ of the analyzed strains, and only 43 of the non-core genes were absent frequently and present in less than $20 \%$ of the strains (Figure 1). These genes are BP0910-34, BP1135-41, BPP0511-12, and BPP2339-47. Besides the variable genes found in this study, previous studies have suggested that 76 additional genes are missing in at least one strain [42,44] (Additional file 6, Table S5). Based on our studies and reports by others, a total of 589 variable genes have been described for B. pertussis. Thus, $15.2 \%$ of the pan-genome is variable, while 3,282 genes (84.8\% from pan-genome) are shared among all analyzed strains, and form the core genome of B. pertussis (Additional file 7, Table S6). The distribution of core and variable genes in the $B$. pertussis Tohama I genome is illustrated in Figure 2 (see also Additional file 8).

\section{Identification of Clusters of Orthologous Groups (COG) enriched for variable genes}

The proportions of the variable genes with respect to their functional category are shown in Figure 3. Genes involved in housekeeping functions (2,185 in total), such as small molecule metabolism and macromolecule metabolism, were found to be relatively conserved; variable genes accounted for only $8 \%$. In contrast, the variable genes accounted for $16 \%$ of the total genes in the other 8 categories (i.e. transport and binding proteins, regulatory functions, cellular processes, mobile and extra chromosomal element functions, hypothetical proteins, signal transduction, unclassified and unknown function). In particular, genes involved in transport and binding, hypothetical genes and those encoding unclassified functions are overrepresented in the variable genes by $11 \%, 19 \%$ and $25 \%$, respectively. Core genes are overrepresented in the genes involved in energy metabolism and most of the genes involved in macromolecule metabolism (Figure 3). Variable genes are enriched for pseudo genes, since we found that $12.5 \%$ of the missing genes are pseudo genes, while $9.6 \%$ of the Tohama I genes are pseudo genes.

\section{Lineage relationships revealed by phylogenetic analysis}

Next, we investigated the geographic and temporal differences in B. pertussis strains analyzed in this study. In order to be able to perform cluster analysis on the CGH data, RDs were categorized as either present (1), or absent (0) in each strain (Additional file 3, Table S2). In order to evaluate the relationships among $B$. pertussis strains, we performed a clustering analysis on the binary CGH data by the unweighted-pair group method using average linkages (UPGMA). This analysis generated a similarity matrix, as well as a UPGMA tree. Based on the similarity matrix, a minimum spanning tree was constructed to give a phylogenetic structure of 148 strains (Figure 4A and 4B). Based on the minimum spanning tree, 148 strains formed 40 different gene content types (GC-types) that were assigned into one large complex and two very small complexes.

We compared the frequencies of GC-types in three periods: 1949-1964, 1965-1992 and 1993-2008 (Table 3) (Figure 5). The most common GC-types are GC-type 1 (25\% of the strains) and GC-type 2 (23\% of the strains). The remaining GC-types found at frequencies lower than $8 \%$ were pooled together. Almost all $(84 \%)$ of the strains analyzed from the first period were Dutch strains, because only a few strains from this period were available. In the $1^{\text {st }}$ period a dominant GC-type was not found, while 11 different GC-types were detected at a frequency of $5-11 \%$. In the $2^{\text {nd }}$ period, strains carrying GC-type 1 increased in frequency to $41 \%$, however, the frequency of these strains decreased again to $19 \%$ in the $3^{\text {rd }}$ period. Strains of GC-type 2 were detected at a frequency of only $5 \%$ in the $2^{\text {nd }}$ period, but were predominant $(43 \%)$ in the $3^{\text {rd }}$ period. The differences observed

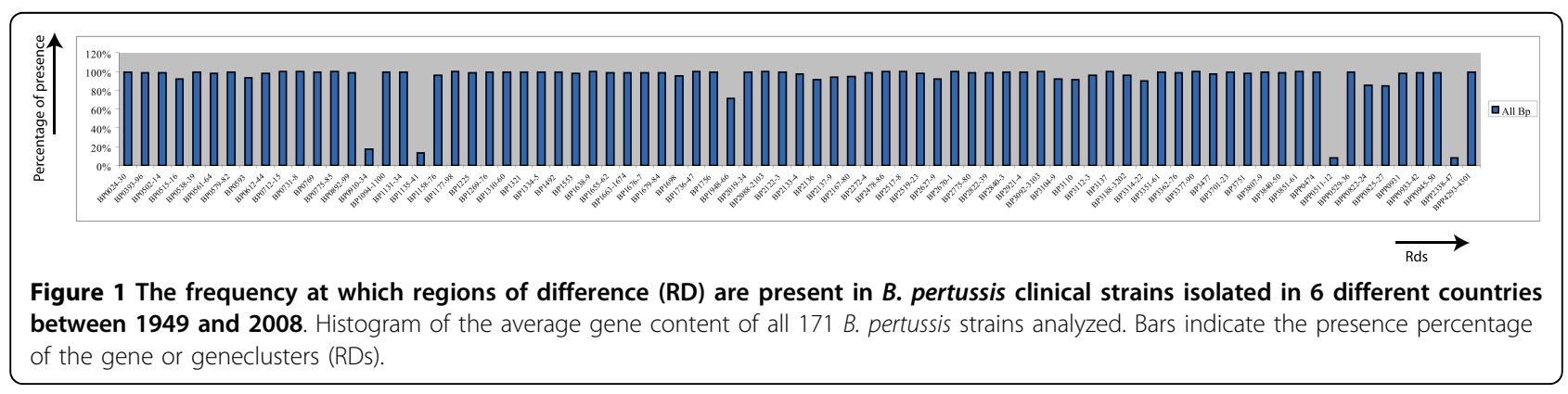




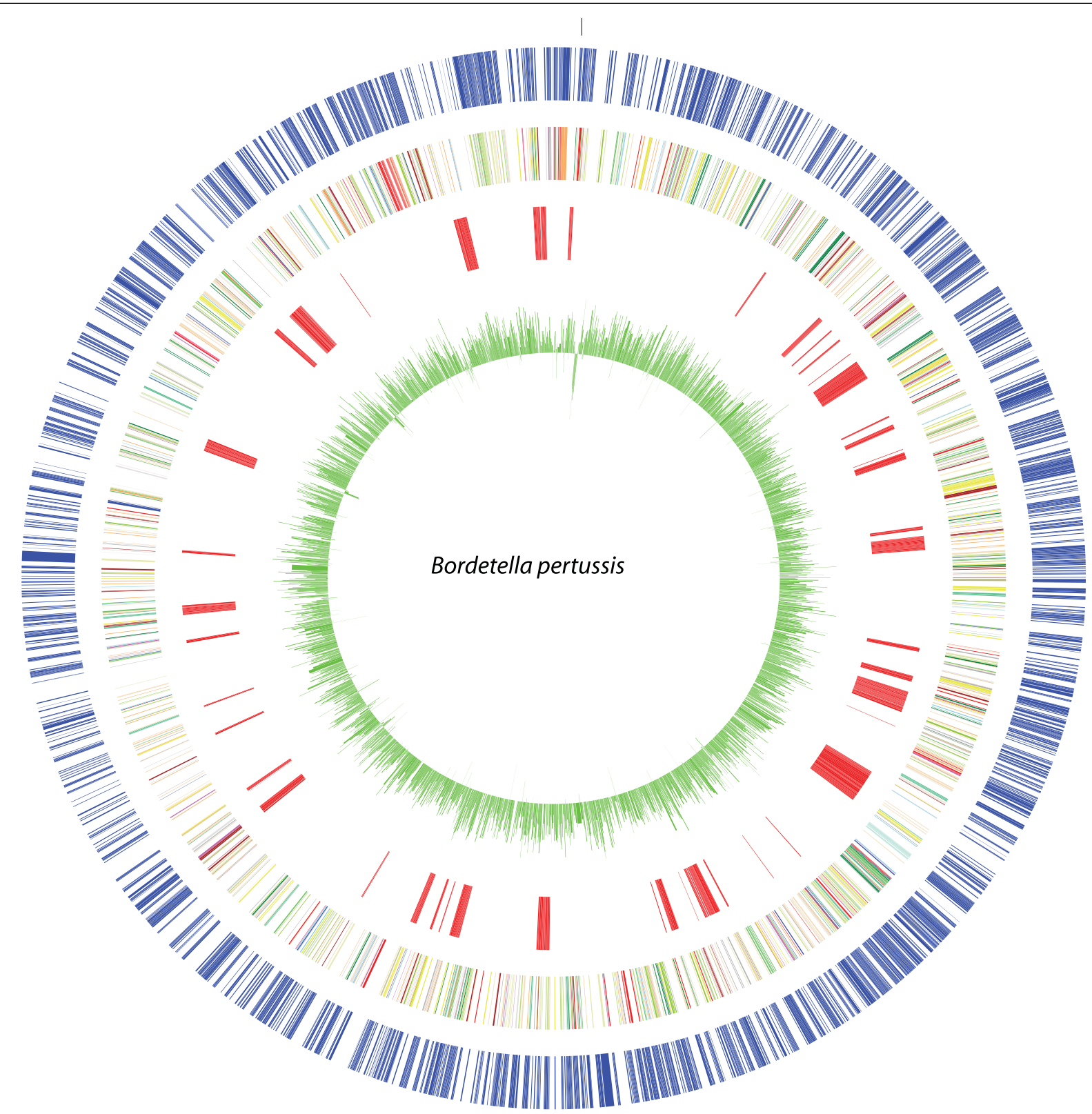

Figure 2 The variable genes identified with microarray in this study, mapped onto circular B. pertussis genome Tohama I. Variable genes not present in the Tohama I genome are not mapped in this figure. From the outside in, the outer circle 1 (blue) shows the position of the genes on the + strand. Circle 2 shows the COG functional categories on the + strand. The COG domains are color coded according to their main functional categories (for color code see additional file 8, Table S9). Circle 3 (red) indicates the position of the variable genes on the Tohama I genome. Circle 4 shows the GC \% percentage of the Tohama I sequence.

in GC-type frequencies of different countries may be influenced by many factors, such as differences in vaccine history or other geographic factors. Nevertheless, we observed that strains carrying the same, or similar, gene content were found in different countries within the same time-period, and have seen no clear geographic specificity of the B. pertussis strains. For example, strains with the GC-type 1 and GC-type 2 were found in 4 and 3 different countries, respectively. Due to differences in vaccine history, specific lineages can arise in a country. For example, in the Netherlands, we observed an increase in strains with GC-type 4, which was the result of a change in the vaccine dose, and ultimately led to the 1980 s pertussis epidemic. However, strains with this gene content were not found in other countries.

In order to determine if the gene content was linked to specific alleles, we combined the gene content data 


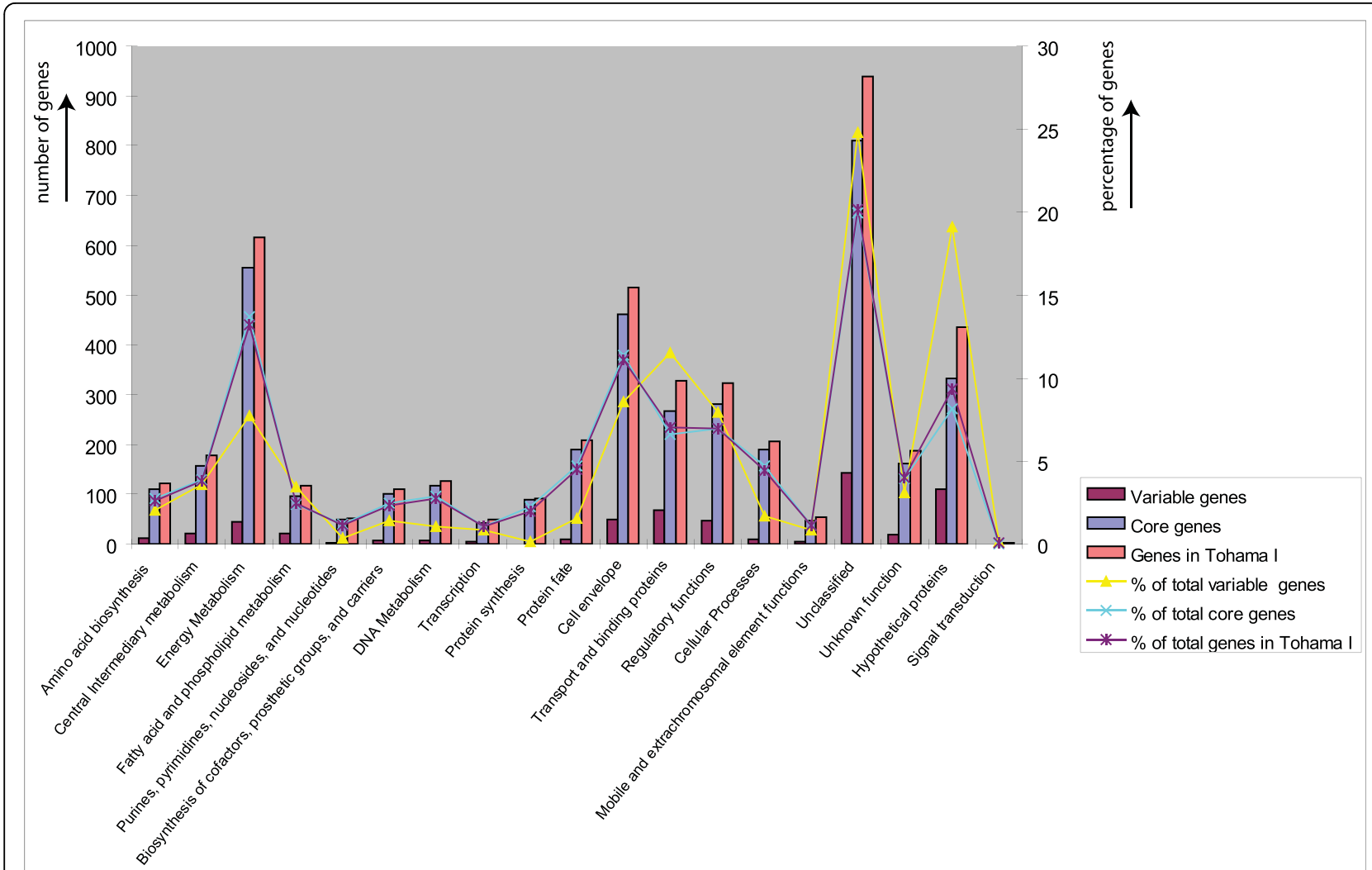

Figure 3 Functional categories of core and variable genes in B. pertussis. The height of each bar represents the number of variable (purple), core (blue) and genes present in Tohama I (orange) indicated in specific gene categories. The lines indicate the percentages of the total, variable genes (yellow), core genes (blue) or genes in Tohama I (purple) in each category.

with the MLST (PtxP-Fim3-Prnregion1) data. The gene content of $B$. pertussis strains was found to correlate highly with the $p t x P$ type of the analyzed strains (Figure 4B). Moreover, clustering based on MLST-type (PtxPFim3-Prnregion1) data resulted in a similar structure (Figure 4C) compared to clustering based on GC-type data (Figure 4B). In our previous study, we found that all Dutch strains carrying the $p t x P 3$ allele were characterized by the absence of the BP1948-66 gene cluster [45]. Here, we confirm the association of the ptxP3 allele with the absence of these genes also found in strains isolated from Sweden, Australia and Japan (n total=39). Figure 6 shows the average gene content of all analyzed strains analyzed $(\mathrm{n}=171)$ and is organized by $p t x P$ type. The $p t x P 3$ strains also miss BP0910-34 and BP1135-41, BPP2338-47 and BPP0511-2 besides the already mentioned RD: BP1948-66 (Figure 6). Furthermore, we also found that $p \operatorname{txP2}$ strains $(\mathrm{n}=9)$ are characterized by the absence of BP0593, BP2627-9, BP310410, BP3314-22, and BPP0474 (Figure 6). ptxP6 $(\mathrm{n}=9)$ strains are characterized by the presence of all RDs except for, BPP0822-4, BPP0825-7, BPP2338-47 and BPP0511-2 (Figure 6). Finally, the ptxP1 strains $(\mathrm{n}=91)$ miss BPP2338-47 and BPP0511-2, as well as BP0910-34 and BP1135-41 in most of the ptxP1 strains. The ptxP1 strains are more diverse in gene content as several lineages were identified. A lineage of $p t x P 1$ strains expanded in the 1980's is characterized by the absence of BP1698 and BP2167-80 (Figure 4B). A second ptxP1 clone was detected in the Netherlands after the year 2000 , and is characterized by the absence of BPP0822-4 and BPP0825-7. A single strain isolated from the Netherlands in the year 2008 carries the ptxP13 allele and also has the same gene content (Figure 4B).

\section{Estimation of genome size}

We calculated an approximate genome size for each strain based on the CGH data. The total number of genes per genome varied between 3,851 and 3,684 genes. The genome size of the $B$. pertussis Tohama I strain $(4,086,186 \mathrm{bp})$ [47] was used as the starting point. We added the gene size for additional genes and subtracted the gene size for genes scored as being absent in a particular strain. Since microarrays can only detect genes present on the microarray, we estimated the genome size of these strains based on the absence/presence 


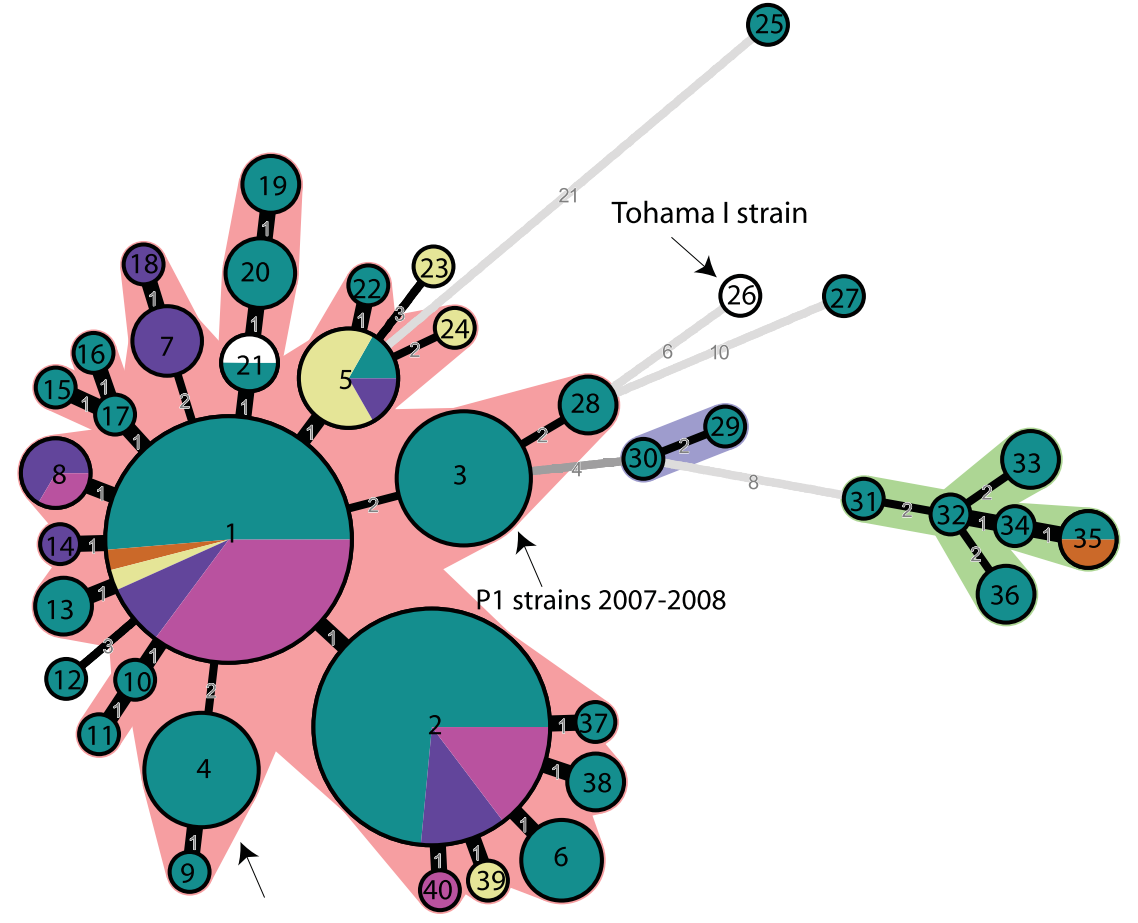

P1 strains epidemic 80's

B

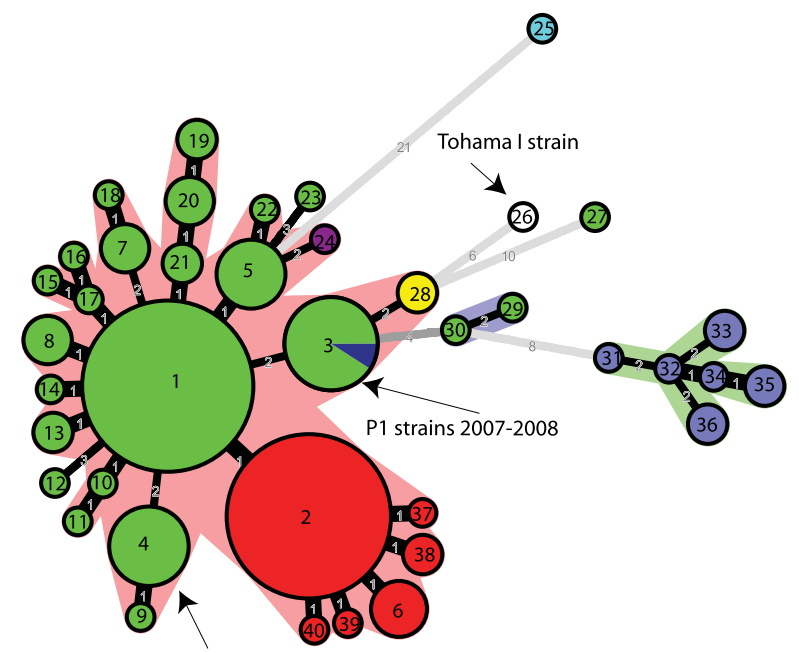

P1 strains epidemic 80's
C

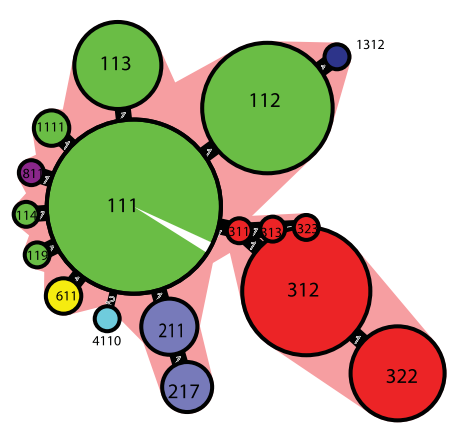

Clustering based on MLST-type

Figure 4 Minimum spanning tree of 148 B. pertussis strains. A. Each circle (node) represents a different GC-type, indicated by the number in the middle of the circle. The size of the circle corresponds to the number of strains within the particular GC-type. The number along the edge reflects the phylogenic distance between each neighboring node. A thicker edge corresponds to a shorter phylogenic distance. Color is based on country of isolation: Green $=$ Netherlands, Pink = Sweden, Yellow = Japan, Purple = Australia, Brown = Dutch vaccine strains 509 and 134 , White $=$ Tohama I strain, Wellcome 28 strain. $\mathbf{B}$. Minimum spanning tree as in Figure 4A, color based on $p t \times P$ type. Green $=p t \times P 1, B l u e=p t x P 2$, Red $=p t x P 3$, Turquoise $=p t \times P 4$, Yellow $=p t \times P 6$, Purple $=p t x P 8$ and Darkblue $=p t x P 13$, White $=$ Tohama I strain. C. Minimum spanning tree based on MLST-types, MLST designation was based on the allele number in the order ptxP, fim3 and prn region 1 (e.g. MLST 113 represents strains with ptxP1, fim3-1 and prn3). Each circle represents a different MLST-type, indicated by the number in the middle of the circle. The number along the edge reflects the phylogenic distance between each neighboring node. A thicker edge corresponds to a shorter phylogenic distance. Color code is as described in Figure 4B. 


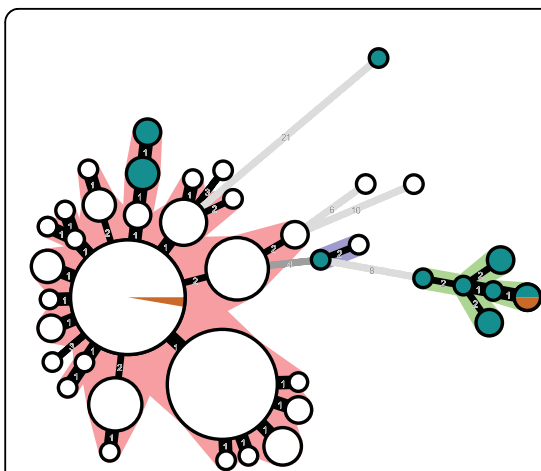

1949-1964

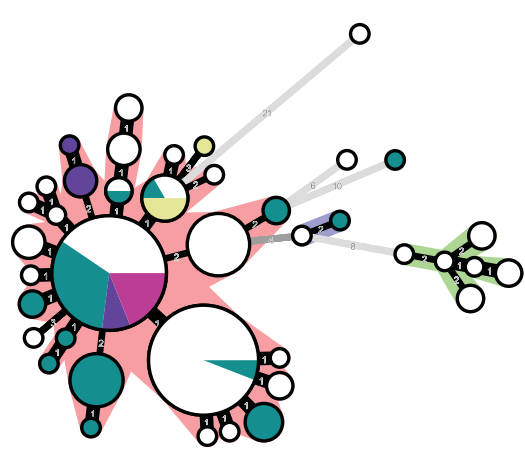

1965-1992

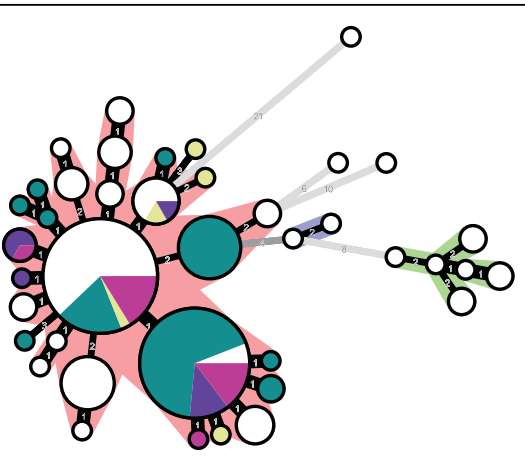

1993-2008

Figure 5 Gradual change in gene content in B. pertussis strains. Minimum spanning tree as shown in Figure $4 \mathrm{~A}$, but only strains isolated in indicated time period are colored. Color code is as described in Figure 4A.

of the 3,871 genes of the $B$. pertussis pan-genome only. Figure 7 shows the estimated genome sizes for all 171 strains organized by isolation date. Remarkably, the genome size of $B$. pertussis strains appears to be significantly decreasing progressively $(\mathrm{P}<0.001)$. A decrease in genome size, over time, was observed in strains isolated from the Netherlands, Sweden, Japan and Australia. However, we could not detect a decrease in genome size of Kenya and Senegal strains since strains from different isolation dates were not available. Strains with the same estimated genome size were found in different countries. These strains carried the same gene content (GC type), but different MLST types (Additional file 3, Table S2) which suggested that they did not simply arise from clonal expansion. Two major outliers exhibiting a smaller genome were also found in the Netherlands.

The largest genome size is estimated to be 4,124,398 bp (strains B0558 and B0572 isolated respectively in 1949 and 1952) and the smallest is 3,937,304 bp (strain B0295 isolated in 1978). The maximum size difference is $187,094 \mathrm{bp}$. The core genome $(3,282$ genes $)$ is theoretically the smallest genome with which $B$. pertussis can survive. Based on the size of the present genes, the size of the core genome is estimated to be $3,485,846 \mathrm{bp}$.

\section{Discussion}

The main purpose of the present study was to analyze the changes in gene content of the $B$. pertussis population in the Netherlands and five other countries between 1949 and 2008. This analysis was conducted using microarray-based CGH methods in order to gain insight into the dynamics of the B. pertussis population. Microarray-based CGH has been widely used to assess the genome variability among bacterial species or closely related bacteria. Given that sequencing of strains on a large scale is still time-consuming and laborious, CGH may resolve the problem to some extent by applying the available genome sequence information. This method can supply additional information about the genome composition and also provide the opportunity to analyze many more unsequenced strains on a genomic scale. Even though this technique has several limitations, we believe that the use of CGH technology, combined with confirmatory PCRs, allows sufficient assessment of the genetic diversity and gene content among $B$. pertussis strains. The high-throughput capability of microarrays enabled us to analyze more than 170 strains. One limitation of microarray-based analysis is that the detection of elements is limited to the presence of a gene in the

Table 3 Frequencies of GC-types during 1949-964, 1965-1992 and 1993-2008

\begin{tabular}{|c|c|c|c|c|c|c|c|c|c|c|c|c|}
\hline \multirow[b]{2}{*}{ Country } & \multicolumn{4}{|c|}{ 1949-1964 } & \multicolumn{4}{|c|}{ 1965-1992 } & \multicolumn{4}{|c|}{ 1993-2008 } \\
\hline & $\begin{array}{c}\text { GC-type } \\
1\end{array}$ & $\begin{array}{c}\text { GC-type } \\
2\end{array}$ & $\begin{array}{c}\text { Other GC- } \\
\text { types }\end{array}$ & $\mathrm{N}$ & $\begin{array}{c}\text { GC-type } \\
1\end{array}$ & $\begin{array}{c}\text { GC-type } \\
2\end{array}$ & $\begin{array}{c}\text { Other GC- } \\
\text { types }\end{array}$ & $N$ & $\begin{array}{c}\text { GC-type } \\
1\end{array}$ & $\begin{array}{c}\text { GC-type } \\
2\end{array}$ & $\begin{array}{c}\text { Other GC- } \\
\text { types }\end{array}$ & $\mathrm{N}$ \\
\hline $\begin{array}{l}\text { The } \\
\text { Netherlands }\end{array}$ & 0 & 0 & 100 & 16 & 32 & 5 & 62 & 37 & 14 & 47 & 39 & 49 \\
\hline Sweden & 0 & 0 & 0 & 0 & 100 & 0 & 0 & 7 & 46 & 38 & 15 & 13 \\
\hline Australia & 0 & 0 & 0 & 0 & 43 & 0 & 57 & 7 & 0 & 50 & 50 & 8 \\
\hline Japan & 0 & 0 & 0 & 0 & 0 & 0 & 100 & 3 & 20 & 0 & 80 & 5 \\
\hline Other & 33 & 0 & 67 & 3 & 0 & 0 & 0 & 0 & 0 & 0 & 0 & 0 \\
\hline Total & 5 & 0 & 95 & 19 & 41 & 4 & 55 & 54 & 19 & 43 & 39 & 75 \\
\hline
\end{tabular}

GC-type frequencies are given in percentages

38 GC-types are found in low frequencies: GC-types 3-40. 


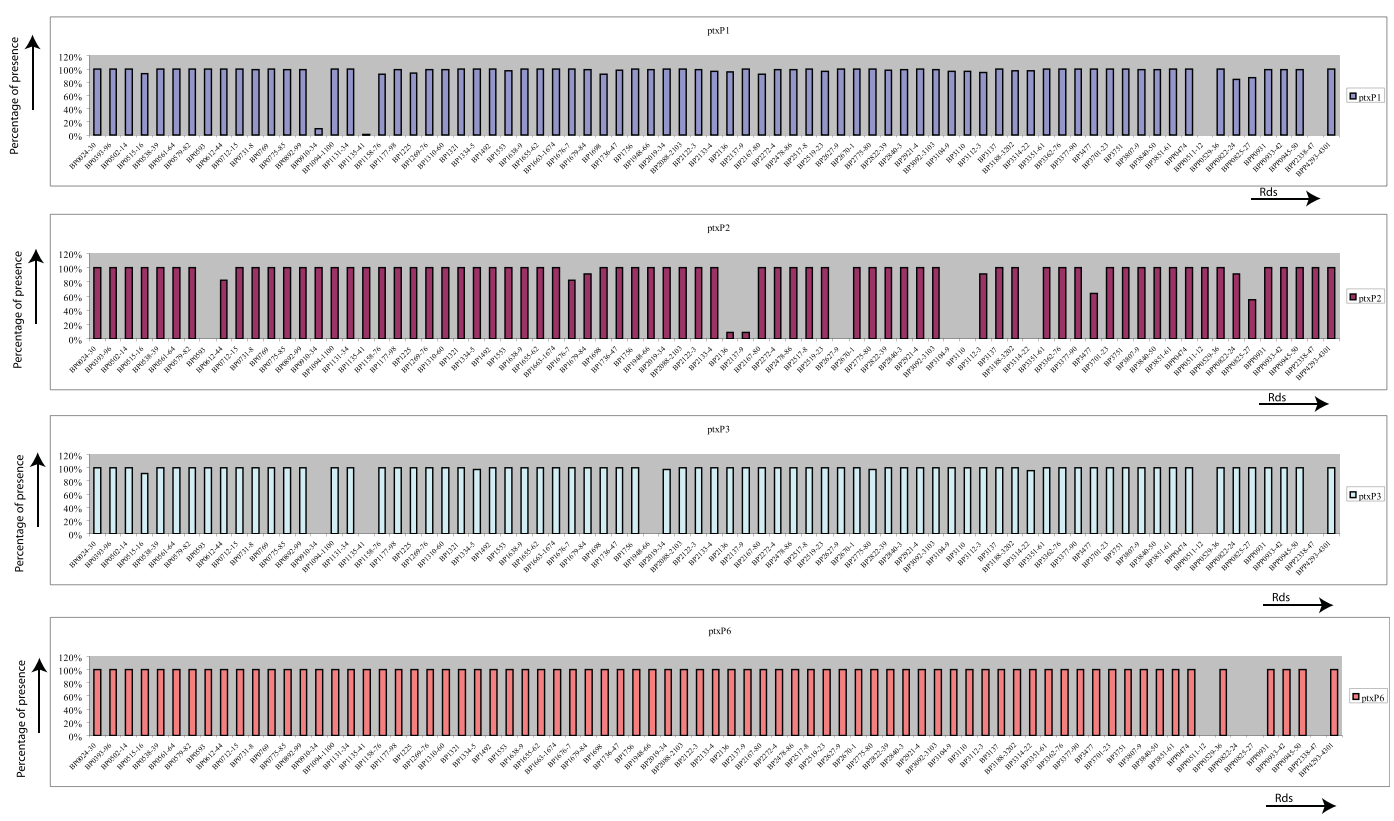

Figure 6 Histogram of the average gene content of strains carrying ptxP1, ptxP2, ptxP3 and ptxP6 types. Bars indicate the presence of the gene or geneclusters in all strains analyzed with a particular $p t x P$ type, $\operatorname{ptx} P 1(n=91), p t x P 2(n=9), p t x P 3(n=39)$ and $p t x P 6(n=9)$.

microarray. In these studies, we used a microarray that is based on the sequence of the Tohama I B. pertussis strain, as well as all of the extra genes found in $B p p$ strain 12822 and $B b$ strain RB50. The Tohama I strain was shown not to be a good representative for $B$. pertussis strains [49]. Full genome DNA sequencing of three other B. pertussis strains by Bouchez et al [48] showed that not all of the novel genes were found in the Tohama I strain, but originated from the $B p p$ or $B b$ species. Since $B$. pertussis does not appear to acquire any new genetic material $[1,42,49]$, we expect that if novel genes are present in the $B$. pertussis strains analyzed in these studies, they are likely to originate from $B p p$ or $B b$ species. By using a Bordetella pan-microarray, most of the genes present in the $B$. pertussis strains will be covered. Future DNA sequencing of additional $B$. pertussis strains will demonstrate if this assumption is justified. In this study, indeed the analysis of $171 \mathrm{~B}$.

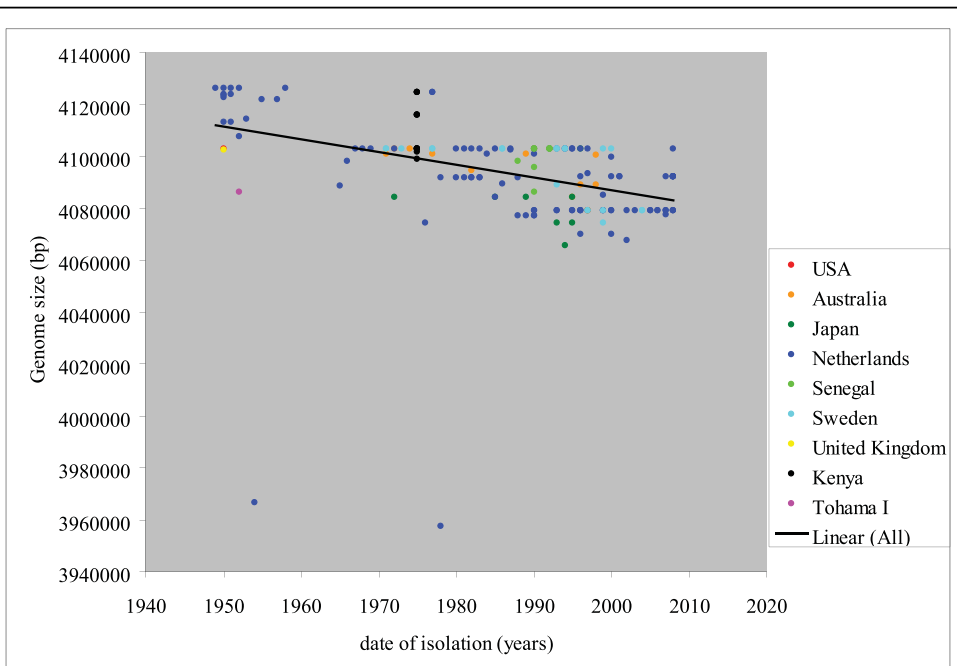

Figure 7 Decrease in genome size in time. Each dot stands for the calculated approximate genome-size of each strain plotted against the isolation year $(n=171)$. The color of the dots is based on the country of isolation. Strains with the same genome size and isolated in the same isolation year will be visible as one dot. 
pertussis strains identified the presence of 12 new genes in the $B$. pertussis species, which originate from the $B$. parapertussis/B. bronchiseptica species.

$\mathrm{CGH}$ analysis for a large series $B$. pertussis strains, isolated in six different countries, has resulted in an estimate of the core genome composition of $B$. pertussis. This analysis has also suggested the degree and nature of the genome flexibility between strains. A total of 3,282 genes were identified as belonging to the core genome. These genes were found in every strain analyzed until present time (this study and [42-45]), and appear to be essential to the lifestyle of this bacterium. The accessory (variably present) portion (589 genes) of the $B$. pertussis genome corresponds to about $15 \%$ of the pan- $B$. pertussis genome. Genes lost, assumed to not to be essential for $B$. pertussis survival in the human host, are enriched for genes involved in transport and binding, hypothetical genes and genes encoding unclassified functions. Accessory genes were confined to certain regions (RDs) in the chromosome, mostly flanked to an IS element (ISE) on at least one side of the RD. The IS 481 element, which is abundantly present (238 times) in the $B$. pertussis genome of the Tohama I strain, may be involved in the process of gene loss by facilitating homologue recombination between these perfect repeats within the genome. Previous studies have shown that repeats can be promoters of gene deletion $[50,51]$, or can also result in large scale chromosomal rearrangements leading to disruption of the ancestral gene order [1].

Three main forces have been found to shape genome evolution; gene gain, gene loss and gene change [52]. Gene loss seems to be an important event in the genomic evolution of the $B$. pertussis species. B. pertussis evolved from a $B$. bronchiseptica-likeancestor probably by large scale gene loss [47]. Much of this loss is most likely due to ISE-mediated deletion events and/or ISE mediated rearrangements, which reshaped the genome presumably to benefit from increased virulence expression. In evolution from $B$. bronchiseptica to B. pertussis the genes that are lost or inactivated are generally those involved in membrane transport, small molecule metabolism, regulation of gene expression and synthesis of surface structures [47]. It seems that gene loss began during the evolution from $B$. bronchiseptica, and is continuing during the evolution of $B$. pertussis. This conclusion is supported by the results presented in this study that illustrate a progressive decrease in the genome size over time in strains isolated in different countries. Moreover, the genes that were lost exhibited similar functions as the genes lost in the evolution from $B$. bronchiseptica to $B$. pertussis (see above). Gene loss in $B$. pertussis has been previously reported for Finnish [44] and French B. pertussis strains [48]. However, to our knowledge, such a rapid decline in gene loss during a period of 60 years has not yet been described. The loss of genetic material is a dynamic, ongoing process that is not specific for one country, but observed in several areas of the world. In other examples of bacteria gene loss, the process has been described as a progressive purging of unnecessary genes from the genome [53]. Bacteria appear to prefer gene deletions, which could account for a general drive to lose DNA. It is generally assumed, that the bacterial deletion which offers the least negative fitness effect on the host will be selected. However, gene loss can lead to benefits for the pathogen as well, because some gene products are detrimental to pathogenic lifestyle. For example, loss of the cadA gene from the Shigella bacterium has been correlated with an increase of Shigella pathogenicity [54]. Additionally, the preferential loss of bacterial cell surface determinants has been shown to result in an increase in virulence by reducing the number of targets that could be recognized by the human immune system [55].

An intriguing question is what other factors influence the size and content of bacterial genomes? The introduction of vaccination against pertussis has been associated with changes in the $B$. pertussis population $[12,36]$. Thus, we investigated whether pertussis vaccination, during several decades, could influence the size and genomic content of the $B$. pertussis population. Therefore, B. pertussis strains from countries with different pertussis vaccination histories were analyzed. Our collection of $B$. pertussis isolates were divided into time periods of significant events that were observed in the epidemiology of pertussis. In order to gain more insight into how the $B$. pertussis strains are related, we used the genomic content overview of the $B$. pertussis isolates to construct a phylogenetic structure. Recently, this method was also used, in a similar manner, to decipher the microevolution of $V$. parahaemolyticus [40].

Clustering based on genomic content showed that $B$. pertussis strains isolated in different countries are mostly similar and did not reveal a particular geographic region of a specific strain. However, an analysis of the gene content of $B$. pertussis strains over time demonstrated a gradual change in gene content over a period of 60 years (Figure 5 and Table 3). In the Netherlands, strains that were found approximately 60 years ago cannot usually be isolated today. In the last 15 years, strains with a different gene content (GC-type 2) have emerged in several countries. The increase of these strains has most likely caused or influenced the resurgence of pertussis in many countries in the last decade [10-12]. In general, strains have changed in the Netherlands, Sweden and Japan, somewhat irrespective of any difference in vaccination history. It is remarkable that the gene content of strains isolated during certain timeframes is 
similar for all countries, even in the countries with low vaccination coverage. These results suggest that the differences in vaccination history have little or no influence in this process.

On the other hand, in the Dutch B. pertussis population we have seen changes that seem to be influenced by alterations in herd immunity. For example, GC-types 31-36 strains, similar to the vaccine 509-strain, appear to be completely removed from the population following the commencement of vaccination. In contrast, strains with similar gene content to the other vaccine strain 134 (e.g. GC-type 1), have persisted until at least 2008. Additionally, shortly after a change in the vaccine dose in the Netherlands, we have detected the expansion of a clone of $B$. pertussis strains, characterized by the absence of BP1698 and BP2167-80, and identified as GC-types 4 and 9. This clone, also characterized by MLVA types 130, 132, 134 and 137 [21] was able to expand between 1978 and 1988, leading to a pertussis epidemic between 1983 and 1988. However, this clone disappeared again following restoration of the vaccine dose to the original level. Herd immunity was possibly lost because of a decline in vaccine-derived immunity, which was a result of a change in the vaccine composition. This deviation appears to have selected for a change in the composition of circulating $B$. pertussis strains. In 2007-2008, we found the expansion of another clone of $B$. pertussis strains with an additional deletion (e.g. BPP0822-27). It is not yet known what factor induced the expansion of these strains, although the introduction of the ACV in 2005 in the Netherlands may be involved. However, we detected a single strain with the same gene content for the first time in 1996. In Sweden, where vaccination was ceased for a longer period, we did not see the rise of new $B$. pertussis clones that were involved in epidemics. This may possibly be due to the low number of isolates tested. During the last 15 years, the expansion of $B$. pertussis strains in multiple countries that carry the ptxP3 allele $[18,45]$, may also have been influenced by intensive pertussis vaccination for half a century. Since pertussis has shifted to older age groups $[11,56]$ in immunized populations during the last decade, it has been suggested that $B$. pertussis has adapted to the host population with waning immunity, in order to maintain the bacterial reservoir among older hosts [18,57]. Mooi et al [18] proposed that strains surviving better in these hosts are being selected for by vaccination of young infants. Recently, it was shown that the rise of strains carrying the $p t x P 3$ allele, which are also characterized by a particular gene content [45] (GC-types 2, and its derivatives) and seem to have a benefit in older hosts, has contributed to the resurgence of pertussis in the Netherlands [18]. Thus, the size and gene content of the $B$. pertussis genome appear to be influenced by vaccination by herd immunity. Immune pressure may select for certain strains with a particular advantage, and which may be linked to specific gene content. The fact that we see the same or similar strains in different countries during certain time periods suggests that an important advantage for these strains may be their capability to spread throughout the immunized population. Importantly, strains with the same GC-type were found to possess different MLST types, which suggest that they are not a single clone.

In our previous study we found that all Dutch strains carrying the ptxP3 allele were characterized by the absence of the BP1948-66 gene cluster [45]. In this study, we confirmed the similarity of the gene content of strains carrying the $p t x P 3$ allele in strains isolated in different countries. Moreover, we found that the $p t x P$ allele is a good marker for strains that have similar gene content, since also the ptxP2 and ptxP6 strains are associated with the absence or presence of specific gene clusters (Figure 6). This indicates that strains with different $p$ txP types have different genetic backgrounds and form different lineages. Thus, these strains do not differ only in one point mutation, and therefore specific properties of these strains can also be related to this typical gene content. The $p \operatorname{txP} 1$ strains are the most diverse in gene content although most gene clusters are typically lost in one strain or a specific group of strains. The ptxP1 strains missing BP0910-33, BP1135-41, BPP0511-2 and BPP2338-47 has the most single locus and double locus variants indicating that this is the older type. Strains with these characteristics are found in at least five different countries. The minimum spanning tree clearly showed that the $p t x P 3$ clone emerged from the $p t x P 1$ strain.

\section{Conclusions}

In conclusion, an overview of genomic contents of a large collection of isolates from different countries allowed us to derive a core genome of B. pertussis. Clustering based on CGH analysis showed that strains isolated in different countries are highly similar in gene content. Furthermore, strains with the same $p t x P$ type, exhibit great similarity in gene content suggesting that they form distinct lineages. Additionally, the CGH data revealed that the genome size of $B$. pertussis strains has decreased progressively over a period of 60 years. Our results show that $B$. pertussis is dynamic and is continuously evolving. This process seems to be influenced by adaptive evolution. Seemingly, there is selection for certain strains with smaller genomes. Although other factors may also influence the selection for these strains, these strains might benefit in the host with waning immunity by having lower cost of energy, with little negative effect on the host, or by removing gene 
products that are detrimental to the pathogenic lifestyle in older hosts.

\section{Methods \\ Strains}

B. pertussis isolates were isolated between 1949 and 2008 in six different countries; the Netherlands, Sweden, Australia, Kenya, Senegal and Japan. The strains selected for CGH analysis included the vaccine strains that were part of the Dutch WCV used before 2005. Other strains were selected based on frequency of occurrence of MLST types in each time period (see additional file 9, Table S8 for MLST frequencies). Thus, strains selected are representative of the most prevalent MLST-types in each time period. Swedish strains were selected based on Pulse Field type in accordance with frequency of occurrence. This work does not require approval of the ethical commission.

\section{Culture of strains and DNA isolation}

The $B$. pertussis strains used for microarray analysis in this study are listed in additional file 3, Table S2. Strains were cultured for 72 hours on Bordet-Gengou agar plates at $35^{\circ} \mathrm{C}$. Subsequently, they were grown at $35^{\circ} \mathrm{C}$ in Verweij medium (NVI, Bilthoven, Netherlands) with $200 \mu \mathrm{g} \mathrm{ml}^{-1}$ heptakis (2, 6-di-o-methyl)- $\beta$-cyclodextrine for 24 hours while being shaken at $200 \mathrm{rpm}$. Chromosomal DNA was isolated using the Promega Wizard ${ }^{\circ}$ Genomic DNA Purification Kit (Promega, Madison, USA), according to the manufacturer's instructions. The precipitated DNA was dissolved in $100 \mu \mathrm{l}$ of EB (elution buffer, $10 \mathrm{mM}$ Tris, $\mathrm{pH}$ 8.0) (Qiagen, Hilden, Germany).

\section{B. pertussis DNA array design and construction}

The spotted 70-mer oligonucleotides microarray was constructed as described previously in [45]. Probes were spotted non-adjacent and in triplicate. The newly designed microarrays used in this study were custommade pan-Bordetella microarrays using the $8 \times 15 \mathrm{~K}$ format developed by Agilent Technologies, Wilmington, USA. The set of 5,910 60-mer oligonucleotides (60mer), where one oligonulcleotide corresponds to one gene, covered $94 \%$ of the genes in the three sequenced Bordetella strains B. pertussis Tohama I, B. parapertussis 12822 and B. bronchiseptica RB50 strain. B. pertussis oligonucleotides (60-mers) were deduced from the 70-mers used in the spotted microarray. In addition, 98 control probes were included in the microarray, and all spots were printed in duplicate (non adjacent). All userdefined probes were uploaded through the Agilent eArray Web portal (http://earray.chem.agilent.com/earray). All oligonucleotide sequences are listed (additional file 1, Table S1a and additional file 2, Table S1b). Additional details on the microarray production are available through the ArrayExpress microarray data repository (accession number A-MEXP-1695 for the spotted array and accession number A-MEXP-1697 for the extended Bordetella microarray).

\section{Labeling of genomic DNA and Microarray hybridization}

For each CGH hybridization the DNA of a test strain and the reference strain ATCC BAA-589 Tohama I were labeled. Four micrograms of chromosomal DNA of B. pertussis were mixed with $20 \mu \mathrm{l}$ of the $2.5 \times$ Random Primer Mix (BioPrime DNA labeling kit; Invitrogen, Paisley, UK) in a total volume of $41 \mu \mathrm{l}$ of water, boiled for 5 minutes, and then placed on ice. The samples were centrifuged for 2 minutes at 13,200 rpm and were mixed with $5 \mu \mathrm{l} 10 \times \mathrm{dNTP}$ mix [ $2 \mathrm{mM}$ dATP, dCTP and dGTP, $0.5 \mathrm{mM}$ dTTP (Roche, Indianapolis, USA)], $2.5 \mu \mathrm{l}$ of $1 \mathrm{mM}$ Cy3 dUTP (for reference strain) or Cy5 dUTP (for the test strain) (GE Healthcare, Buckinghamshire, UK) and $1 \mu \mathrm{l}$ Klenow polymerase $\left(40 \mathrm{U}_{\mu \mathrm{l}}^{-1}\right)$ (BioPrime DNA labeling kit; Invitrogen, Paisley, UK). The samples were incubated for 3 hours at $37^{\circ} \mathrm{C}$. Subsequently, the test and reference samples were purified separately using CyScribe GFX Purification Kit (GE Healthcare, Buckinghamshire, UK) and then eluted in $60 \mu$ l elution buffer. The incorporation of the Cy-dyes in the labeled target sequences was measured with a NanoDrop spectrophotometer (NanoDrop Technologies).

For the spotted B. pertussis microarray in each CGH experiment, equal amounts of $\mathrm{Cy} 3$ dye (reference) and Cy5 dye (test) were used. The volume of the samples was decreased using a speedvac concentrator (New Brunswick Scientific, Edison, USA). The labeled test and reference samples were mixed together with $79.2 \mu \mathrm{l}$ of hybridization solution [3.44 $\times$ SSC (Invitrogen, Paisley, UK), 0.32\% SDS (Invitrogen, Paisley, UK), $1.0 \mathrm{mg}$ yeast tRNA/ml]. Before loading on the microarray, the hybridization solution was heated for 3 minutes at $100^{\circ} \mathrm{C}$ and $5.8 \mu \mathrm{l}$ of $10 \times$ DIG blocking buffer was added.

For the Agilent pan-Bordetella microarray, $8 \mu \mathrm{l}$ of Cy5 and $8 \mu \mathrm{l}$ Cy3 labeled DNA were used if the specific activity was between $35-55 \mathrm{pmol} / \mu \mathrm{g}$ for Cy3 labeled DNA and between 25-40 pmol/ $\mu$ g for Cy5 labeled DNA. Cy5 and Cy3 labeled DNA were mixed with $4.5 \mu \mathrm{l}$ Agilent $10 \times$ blocking agent, $2 \mu \mathrm{H}_{2} \mathrm{O}$ and $22.5 \mu \mathrm{l}$ Agilent $2 \times$ hybridization buffer. Samples were further treated as described in Agilent protocols (Agilent oligonucleotide array-based CGH for genomic DNA analysis).

Spotted microarrays were hybridized and washed as previously described [45]. Agilent pan-Bordetella microarrays were hybridized and washed following Agilent's protocol (Agilent oligonucleotide array-based CGH for genomic DNA analysis). 


\section{Microarray data mining}

The hybridized slides were scanned at a $10 \mu \mathrm{m}$-resolution using a ScanArray Gx plus microarray scanner (Perkin Elmer) equipped with ScanArrray express software. Images from spotted microarrays were analyzed as previously described in [45]. The images from Agilent pan-Bordetella microarrays were analyzed using ImaGene software (Biodiscovery, El Segundo, USA). Individual arrays were internally normalized between the Cy3 and Cy5 channels by LOWESS normalization [58]. Based on hybridization results of ATCC BAA-589 Tohama I vs ATCC BAA-589 Tohama I, the cut-off for detection of a deletion was set at -1.5 . Thus the normalized intensity ratio of $<-1.5$ indicates the absence of the gene. If the absence of these genes was not previously described, these genes were selected for further analysis by PCR or sequence analysis. The combined normalized data were visualized with TIGR MultiExperimentViewer. The logarithm of the hybridization ratio $[\log 2$ (Cy5/ Cy3)] is indicated in the yellow-black-blue color scale. $[\log 2(\mathrm{Cy} 5 / \mathrm{Cy} 3)]=-3=$ Yellow, $[\log 2(\mathrm{Cy} 5 / \mathrm{Cy} 3)]=0=$ Black, $[\log 2(\mathrm{Cy} 5 / \mathrm{Cy} 3)]=+3=$ Blue.

\section{PCR confirmation and sequence analysis}

For strains analyzed with the spotted $B$. pertussis microarray, additional PCR confirmations were performed. Further PCR analysis was also employed in order to confirm the results predicted by the microarray hybridizations. The PCR primers were designed to target the flanking regions of each deletion so that the amplified region spanned the missing locus. The primers used in this study are listed in additional file 10, Table S9. The PCRs were performed under the following conditions: $20 \mu \mathrm{l}$ total reaction volume, $10 \mu \mathrm{l}$ Hotstart (Qiagen), 10 pmol of each primer (Eurogentec, Seraing, Belgium), 10 ng chromosomal DNA and 5\% DMSO or $1.0 \mathrm{M}$ Betaine (Sigma, St. Louis, USA). The amplification was carried out in a Geneamp PCR system 9700 thermocycler (Applied Biosystems, Foster City, USA) according to manufacturer's recommendations. After amplification, $10 \mu \mathrm{l}$ of each PCR product was observed via $1 \%$ agarose gel electrophoresis with SYBR-Safe (Molecular Probes, Carlsbad, USA) staining. In order to determine the deletion boundaries, PCR products were purified using ExoSAP-IT $^{\ominus}$ (USB, Cleveland, USA). Subsequently the purified PCR products were sequenced using standard Big Dye Terminator v 3.1 (Applied Biosystems, Foster City, USA). Nucleotide sequencing was performed with an Applied Biosystems 3700 DNA Analyzer. Sequence data obtained from the ABI-3700 was compared to the B. pertussis sequence of Tohama I using the DNAsequence analysis program KODON to determine the precise location of each deletion.

\section{Clustering and phylogenetic analysis}

The final determination of absent (0) or present (1) was assigned to each RD for each strain in the $\mathrm{CGH}$ data and analyzed by BioNumerics version 5.1 (AppliedMaths, St. Maartens-Latem, Belgium). Clustering was carried out subsequently by the unweighted-pair group method using average linkages (UPGMA), to calculate a similarity matrix. A minimum spanning tree was built based upon the similarity matrix using Bionumerics version 5.1 .

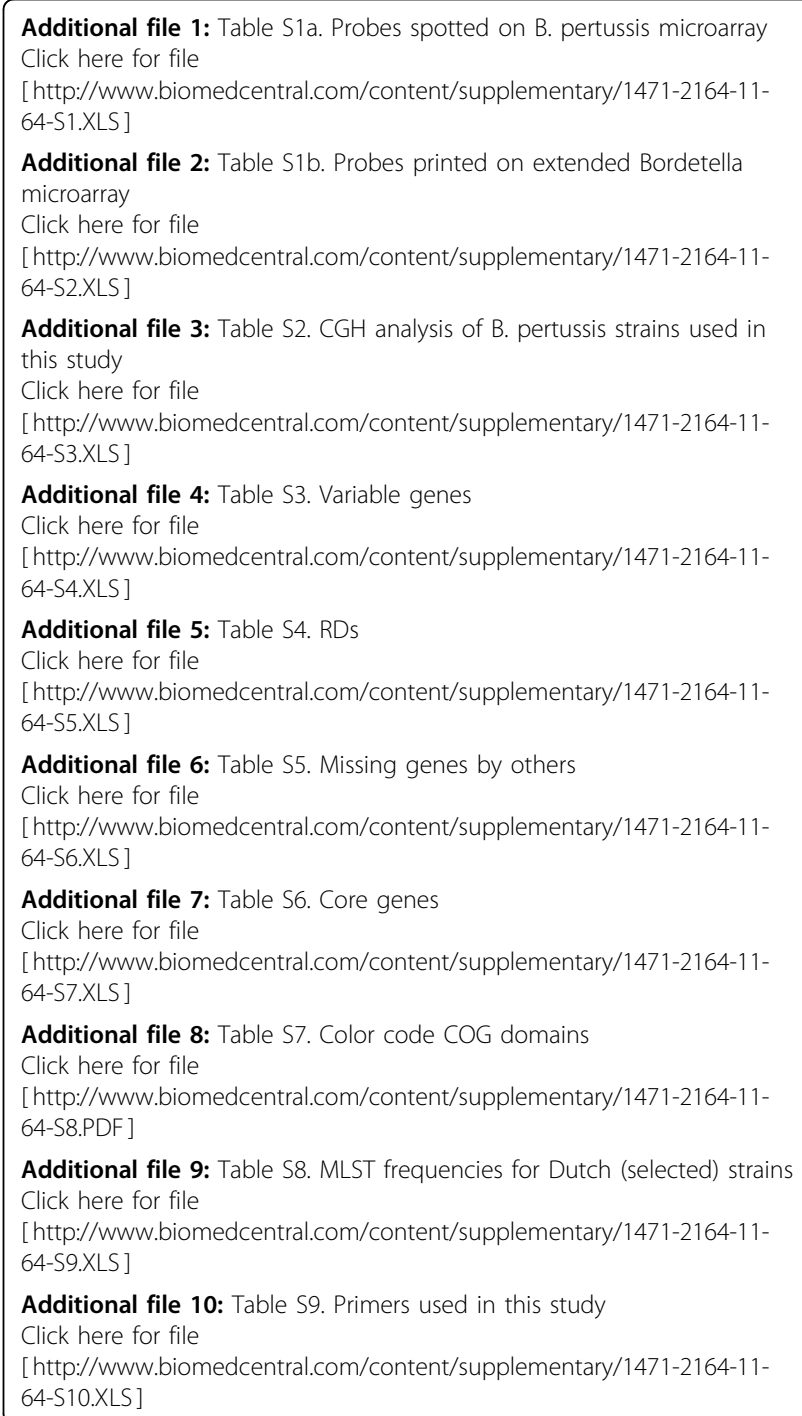

\section{Abbreviations}

CGH: Comparative Genomic Hybridization; WCV: Whole Cell Vaccine; ACV: Acellular Vaccine; ISE: IS element

\section{Acknowledgements}

We are very grateful to Frits Mooi for critical discussion of this work. The authors thank Jeroen Pennings for help with microarray data mining. This 
work was supported by the National institute of Public Health and the Environment through SOR funding.

\section{Author details}

${ }^{1}$ Laboratory for Infectious Diseases and Screening (LIS) Centre for Infectious Disease Control, National Institute for Public Health and the Environment RIVM - Netherlands, P.O. Box 1, 3720 BA Bilthoven, The Netherlands. ${ }^{2}$ Swedish Institute for Infectious Disease Control, Nobels väg 18, S-171 82 Solna, Sweden.

\section{Authors' contributions}

AJK conceived the study, designed the experiments, carried out part of the experiments and data analysis and wrote the manuscript. TvG carried out part of the microarray experiments, PCR confirmations, DNA sequencing experiments. HGJvdH participated in microarray data analysis. AA supplied Swedish strains, carried out PFGE analysis and commented on the manuscript. SvdL carried out most of the microarray experiments, PCR confirmations, DNA sequencing experiments, part of the data analysis and was involved in writing the manuscript. All the authors read and approved the final manuscript.

\section{Received: 9 July 2009}

Accepted: 26 January 2010 Published: 26 January 2010

\section{References}

1. Cummings CA, Brinig MM, Lepp PW, van de PS, Relman DA: Bordetella species are distinguished by patterns of substantial gene loss and host adaptation. J Bacteriol 2004, 186:1484-1492.

2. Zee van der A, Mooi F, Van Embden J, Musser J: Molecular evolution and host adaptation of Bordetella spp.: phylogenetic analysis using multilocus enzyme electrophoresis and typing with three insertion sequences. J Bacteriol 1997, 179:6609-6617.

3. Heininger U, Stehr K, Schmitt-Grohe S, Lorenz C, Rost R, Christenson PD, et al: Clinical characteristics of illness caused by Bordetella parapertussis compared with illness caused by Bordetella pertussis. Pediatr Infect Dis $J$ 1994, 13:306-309.

4. Gueirard P, Weber C, Le Coustumier A, Guiso N: Human Bordetella bronchiseptica infection related to contact with infected animals: persistence of bacteria in host. J Clin Microbiol 1995, 33:2002-2006.

5. Diavatopoulos DA, Cummings CA, Schouls LM, Brinig MM, Relman DA Mooi FR: Bordetella pertussis, the causative agent of whooping cough, evolved from a distinct, human-associated lineage of B. bronchiseptica. PLOS Pathog 2005, 1:e45.

6. Zee van der A, Groenendijk H, Peeters M, Mooi FR: The differentiation of Bordetella parapertussis and Bordetella bronchiseptica from humans and animals as determined by DNA polymorphism mediated by two different insertion sequence elements suggests their phylogenetic relationship. Int J Syst Bacteriol 1996, 46:640-647.

7. Mattoo S, Cherry JD: Molecular pathogenesis, epidemiology, and clinical manifestations of respiratory infections due to Bordetella pertussis and other Bordetella subspecies 1. Clin Microbiol Rev 2005, 18:326-382.

8. He Q, Mertsola J: Factors contributing to pertussis resurgence 10. Future Microbiol 2008, 3:329-339.

9. Crowcroft NS, Pebody RG: Recent developments in pertussis. Lancet 2006, 367:1926-1936.

10. de Melker HE, Schellekens JF, Neppelenbroek SE, Mooi FR, Rumke HC, Conyn-van Spaendonck MA: Reemergence of pertussis in the highly vaccinated population of the Netherlands: observations on surveillance data. Emerg Infect Dis 2000, 6:348-357.

11. Guris D, Strebel PM, Bardenheier B, Brennan M, Tachdjian R, Finch E, et al: Changing epidemiology of pertussis in the United States: increasing reported incidence among adolescents and adults, 1990-1996. Clin Infect Dis 1999, 28:1230-1237.

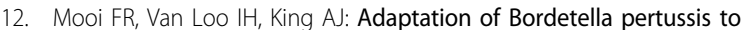
vaccination: a cause for its reemergence?. Emerg Infect Dis 2001, 7:526-528.

13. Mooi FR, van Oirschot H, Heuvelman K, Heide van der HG, Gaastra W, Willems RJ: Polymorphism in the Bordetella pertussis virulence factors P.69/pertactin and pertussis toxin in The Netherlands: temporal trends and evidence for vaccine-driven evolution. Infect Immun 1998, 66:670-675
14. Mooi FR, He Q, van Oirschot H, Mertsola J: Variation in the Bordetella pertussis virulence factors pertussis toxin and pertactin in vaccine strains and clinical isolates in Finland. Infect Immun 1999, 67:3133-3134.

15. Mastrantonio $P$, Spigaglia $P$, van Oirschot $H$, Heide van der $H G$, Heuvelman $K$, Stefanelli $P$, et al: Antigenic variants in Bordetella pertussis strains isolated from vaccinated and unvaccinated children. Microbiology 1999, 145(Pt 8):2069-2075.

16. Cassiday P, Sanden G, Heuvelman K, Mooi F, Bisgard KM, Popovic T: Polymorphism in Bordetella pertussis pertactin and pertussis toxin virulence factors in the United States, 1935-1999. J Infect Dis 2000, 182:1402-1408

17. Berbers GA, de Greeff SC, Mooi FR: Improving pertussis vaccination 1. Hum Vaccin 2009, 5:497-503.

18. Mooi FR, Van Loo IH, van Gent M, He Q, Bart MJ, Heuvelman KJ, et al: Bordetella pertussis strains with increased toxin production associated with pertussis resurgence 2. Emerg Infect Dis 2009, 15:1206-1213.

19. Miller E, Vurdien JE, White JM: The epidemiology of pertussis in England and Wales. Commun Dis Rep CDR Rev 1992, 2:R152-R154.

20. Hallander HO, Gustafsson L, Ljungman M, Storsaeter J: Pertussis antitoxin decay after vaccination with DTPa. Response to a first booster dose $31 /$ 2-6 1/2 years after the third vaccine dose 11. Vaccine 2005, 23:5359-5364.

21. van Gent M, de Greeff SC, Heide van der HG, Mooi FR: An investigation into the cause of the 1983 whooping cough epidemic in the Netherlands 1. Vaccine 2009, 27:1898-1903.

22. Gustafsson L, Hessel L, Storsaeter J, Olin P: Long-term follow-up of Swedish children vaccinated with acellular pertussis vaccines at 3, 5, and 12 months of age indicates the need for a booster dose at 5 to 7 years of age 1. Pediatrics 2006, 118:978-984.

23. Hallander HO, Advani A, Donnelly D, Gustafsson L, Carlsson RM: Shifts of Bordetella pertussis variants in Sweden from 1970 to 2003, during three periods marked by different vaccination programs 13. J Clin Microbiol 2005, 43:2856-2865.

24. Sato $H$, Sato $Y$ : Experience with diphtheria toxoid-tetanus toxoid-acellular pertussis vaccine in Japan 5. Clin Infect Dis 1999, 28(Suppl 2):S124-S130.

25. Watanabe M, Nagai M: Acellular pertussis vaccines in Japan: past, present and future 1. Expert Rev Vaccines 2005, 4:173-184.

26. Quinn HE, Mclntyre PB: Pertussis epidemiology in Australia over the decade 1995-2005-trends by region and age group 4. Commun Dis Intell 2007, 31:205-215.

27. Preziosi MP, Yam A, Wassilak SG, Chabirand L, Simaga A, Ndiaye M, et al: Epidemiology of pertussis in a West African community before and after introduction of a widespread vaccination program 1. Am J Epidemiol 2002, 155:891-896.

28. Patel S, Schoone G, Ligthart GS, Gikken H, Preston NW: Machakos project studies. Agents affecting health of mother and child in a rural area of Kenya. V. Pertussis sentypes in Kenyan children 1974-1975 10. Trop Geogr Med 1978, 30:141-146.

29. Galazka A: Control of pertussis in the world 6. World Health Stat Q 1992, 45:238-247.

30. Caro V, Njamkepo E, Van Amersfoorth SC, Mooi FR, Advani A, Hallander HO, et al: Pulsed-field gel electrophoresis analysis of Bordetella pertussis populations in various European countries with different vaccine policies. Microbes Infect 2005, 7:976-982

31. Elomaa A, Advani A, Donnelly D, Antila M, Mertsola J, Hallander $H$, et al: Strain variation among Bordetella pertussis isolates in finland, where the whole-cell pertussis vaccine has been used for 50 years 9. J Clin Microbiol 2005, 43:3681-3687.

32. Hallander $\mathrm{H}$, Advani A, Riffelmann M, Von Konig CH, Caro V, Guiso N, et al: Bordetella pertussis strains circulating in Europe in 1999 to 2004 as determined by pulsed-field gel electrophoresis 3. J Clin Microbiol 2007, 45:3257-3262.

33. Kourova N, Caro V, Weber C, Thiberge S, Chuprinina R, Tseneva G, et al: Comparison of the Bordetella pertussis and Bordetella parapertussis isolates circulating in Saint Petersburg between 1998 and 2000 with Russian vaccine strains 1. J Clin Microbiol 2003, 41:3706-3711.

34. Lin YC, Yao SM, Yan JJ, Chen YY, Hsiao MJ, Chou CY, et al: Molecular epidemiology of Bordetella pertussis in Taiwan, 1993-2004: suggests one possible explanation for the outbreak of pertussis in 19973 . Microbes Infect 2006, 8:2082-2087.

35. Van Loo $\mid H$, Heide van der HG, Nagelkerke NJ, Verhoef J, Mooi FR: Temporal trends in the population structure of Bordetella pertussis 
during 1949-1996 in a highly vaccinated population. J Infect Dis 1999, 179:915-923.

36. Van Loo IH, Mooi FR: Changes in the Dutch Bordetella pertussis population in the first 20 years after the introduction of whole-cell vaccines. Microbiology 2002, 148:2011-2018.

37. Weber C, Boursaux-Eude C, Coralie G, Caro V, Guiso N: Polymorphism of Bordetella pertussis isolates circulating for the last 10 years in France, where a single effective whole-cell vaccine has been used for more than 30 years 3. I Clin Microbiol 2001, 39:4396-4403.

38. Champion OL, Gaunt MW, Gundogdu O, Elmi A, Witney AA, Hinds J, et al: Comparative phylogenomics of the food-borne pathogen Campylobacter jejuni reveals genetic markers predictive of infection source 6. Proc Natl Acad Sci USA 2005, 102:16043-16048.

39. Dorrell N, Hinchliffe SJ, Wren BW: Comparative phylogenomics of pathogenic bacteria by microarray analysis 2. Curr Opin Microbiol 2005, 8:620-626.

40. Han H, Wong HC, Kan B, Guo Z, Zeng X, Yin S, et al: Genome plasticity of Vibrio parahaemolyticus: microevolution of the 'pandemic group' 3. BMC Genomics 2008, 9:570.

41. Zhang $Y$, Laing $C$, Steele M, Ziebell $K$, Johnson R, Benson AK, et al: Genome evolution in major Escherichia coli 0157:H7 lineages 1. BMC Genomics 2007, 8:121.

42. Brinig MM, Cummings CA, Sanden GN, Stefanelli P, Lawrence A, Relman DA: Significant gene order and expression differences in Bordetella pertussis despite limited gene content variation. J Bacterio/ 2006, 188:2375-2382.

43. Caro V, Hot D, Guigon G, Hubans C, Arrive M, Soubigou G, et al: Temporal analysis of French Bordetella pertussis isolates by comparative wholegenome hybridization. Microbes Infect 2006, 8:2228-2235.

44. Heikkinen E, Kallonen T, Saarinen L, Sara R, King AJ, Mooi FR, et al: Comparative Genomics of Bordetella pertussis Reveals Progressive Gene Loss in Finnish Strains. PLOS ONE 2007, 2:e904.

45. King AJ, van Gorkom T, Pennings JL, Heide van der HG, He Q, Diavatopoulos D, et al: Comparative genomic profiling of Dutch clinical Bordetella pertussis isolates using DNA microarrays: identification of genes absent from epidemic strains 2. BMC Genomics 2008, 9:311.

46. Advani A, Donnelly D, Hallander H: Reference system for characterization of Bordetella pertussis pulsed-field gel electrophoresis profiles 16. J Clin Microbiol 2004, 42:2890-2897.

47. Parkhill J, Sebaihia M, Preston A, Murphy LD, Thomson N, Harris DE, et al: Comparative analysis of the genome sequences of Bordetella pertussis, Bordetella parapertussis and Bordetella bronchiseptica. Nat Genet 2003, 35:32-40.

48. Bouchez V, Caro V, Levillain E, Guigon G, Guiso N: Genomic content of Bordetella pertussis clinical isolates circulating in areas of intensive children vaccination 1. PLOS ONE 2008, 3:e2437.

49. Caro V, Bouchez V, Guiso N: Is the Sequenced Bordetella pertussis strain Tohama I representative of the species? 2. J Clin Microbiol 2008, 46:2125-2128.

50. Gaudriault S, Pages S, Lanois A, Laroui C, Teyssier C, Jumas-Bilak E, et al: Plastic architecture of bacterial genome revealed by comparative genomics of Photorhabdus variants 1. Genome Biol 2008, 9:R117.

51. Treangen TJ, Abraham AL, Touchon M, Rocha EP: Genesis, effects and fates of repeats in prokaryotic genomes 2. FEMS Microbiol Rev 2009, 33:539-571.

52. Pallen MJ, Wren BW: Bacterial pathogenomics 1. Nature 2007, 449:835-842.

53. Andersson DI: Shrinking Bacterial Genomes. Microbe 2008, 3:124-130.

54. Day WA Jr, Fernandez RE, Maurelli AT: Pathoadaptive mutations that enhance virulence: genetic organization of the cadA regions of Shigella spp 2. Infect Immun 2001, 69:7471-7480.

55. Lawrence JG: Common themes in the genome strategies of pathogens. Curr Opin Genet Dev 2005, 15:584-588.

56. de Greeff SC, Mooi FR, Schellekens JF, de Melker HE: Impact of acellular pertussis preschool booster vaccination on disease burden of pertussis in The Netherlands 5. Pediatr Infect Dis J 2008, 27:218-223.

57. Kallonen T, He Q: Bordetella pertussis strain variation and evolution postvaccination 1. Expert Rev Vaccines 2009, 8:863-875.

58. Saeed Al, Sharov V, White J, Li J, Liang W, Bhagabati N, et al: TM4: a free, open-source system for microarray data management and analysis. Biotechniques 2003, 34:374-378. doi:10.1186/1471-2164-11-64

Cite this article as: King et al:: Changes in the genomic content of circulating Bordetella pertussis strains isolated from the Netherlands, Sweden, Japan and Australia: adaptive evolution or drift?. BMC Genomics 2010 11:64.

\section{Submit your next manuscript to BioMed Central and take full advantage of:}

- Convenient online submission

- Thorough peer review

- No space constraints or color figure charges

- Immediate publication on acceptance

- Inclusion in PubMed, CAS, Scopus and Google Scholar

- Research which is freely available for redistribution 